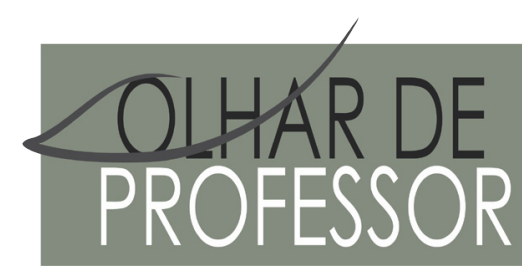

DOI: 10.5212/OLHARPROFR.v.2112.0001

\title{
ÓRGÃOS DOS SENTIDOS NO LIVRO DIDÁTICO DO ENSINO FUNDAMENTAL II: UMA ANÁLISE FUNDAMENTADA EM INDICADORES DE ALFABETIZAÇÃO CIENTÍFICA
}

\author{
SENSE ORGANS IN THE TEXTBOOKS OF ELEMENTARY EDUCATION LL: AN ANALYSIS BASED ON SCIENTIFIC \\ LITERACY INDICATORS
}

\section{ÓRGANOS DE LOS SENTIDOS EN EL LIBRO DIDÁTICODE LA ENSEÑANZA FUNDAMENTAL II: UNA ANÁLISIS FUNDAMENTADA EN INDICADORES DE ALFABETIZACIÓN CIENTÍFICA}

\author{
DANIELA POLLL ${ }^{*}$ \\ GRAZIELA PICCOLI RICHETTI
}

\begin{abstract}
Resumo: O presente trabalho propõe-se a investigar a presença dos indicadores de alfabetização científica na abordagem do conteúdo de órgãos dos sentidos em livros didáticos de Ciências. O corpus de análise foi constituído por quatro coleções de livros didáticos adotados pela rede municipal de ensino de Blumenau para a disciplina de Ciências do segundo ciclo do Ensino Fundamental. Objetivando averiguar a promoção da alfabetização científica na aprendizagem, realizou-se uma pesquisa qualitativa para buscar indícios de textos, imagens, questionamentos e esquemas que possam auxiliar o professor no desenvolvimento da alfabetização científica de seus alunos. Para a análise do material, alguns dos indicadores de AC propostos por Sasseron e Carvalho (2008) foram empregados como critérios de análise. Desta forma, objetivou-se perceber a possibilidade de utilização desse material didático como ferramenta para o desenvolvimento de AC nos estudantes. Pretende-se, com este estudo, auxiliar os professores da rede pública na escolha do material didático a ser utilizado nas aulas do ano letivo subsequente e apresentar possibilidades para o ensino dos órgãos dos sentidos na perspectiva da alfabetização científica.
\end{abstract}

Palavras-chave: Ensino de Ciências. Órgãos dos sentidos. Alfabetização científica.

\begin{abstract}
The present work aims to investigate the presence of indicators of scientific literacy in the approach of the content of sense organs in science textbooks. The corpus of analysis was consisted by four collections of textbooks adopted by the municipal Education Network of Blumenau for the discipline of Sciences of the second cycle of elementary education. Aiming to investigate the promotion of scientific literacy in learning, a qualitative research was carried out to find indications of texts, images, questions and schemes that could assist the teacher in the development of the scientific literacy of students. For the analysis of the material, some of the CA indicators proposed by Sasseron and Carvalho (2008) were used as analysis criteria.Thus, the objective was to perceive the possibility of using this didactic material as a tool for the development of CA in students. This study intends to assist teachers of the public network in choosing didactic materials to be used in the classes of the subsequent school year and to present possibilities for the teaching of sense organs in the perspective of scientific literacy.
\end{abstract}

Keywords: Science teaching. Sense organs. Scientific literacy.

Resumen: El presente trabajo se propone investigar la presencia de los indicadores de alfabetización científica em El abordaje Del contenido de órganos de los sentidos em libros didácticos de Ciencias. El corpus de análisis fue constituido por cuatro colecciones de libros didácticos adoptados por La red municipal de enseñanza de Blumenau

\footnotetext{
* Especialista em Educação Escolar Contemporânea pela Universidade Federal de Santa Catarina - Centro de Blumenau. Professora de Ciências do Ensino Fundamental no Colégio Uni Gaspar e de Biologia do Ensino Médio no Colégio Visão em Blumenau. E-mail:profedanipolli@gmail.com

${ }^{* *}$ Professora adjunta do Departamento de Ciências Exatas e Educação da Universidade Federal de Santa Catarina - Centro de Blumenau. E-mail: graziela.richetti@ufsc.br
} 
para la disciplina de Ciencias del segundo ciclo de La Enseñanza Fundamental. El objetivo de averiguar La promoción de La alfabetización científica em El aprendizaje, se realizó una investigación cualitativa para buscar indicios de textos, imágenes, cuestionamientos y esquemas que puedan auxiliar al profesor em El desarrollo de La alfabetización científica de sus alumnos. Para El análisis del material, algunos de los indicadores de AC propuestos por Sasseron y Carvalho (2008) fueron empleados como criterios de análisis. De esta forma, se objetivo percibir La posibilidad de utilización de ese material didáctico como herramienta para eldesarrollo de AC em lós estudiantes. Se pretende, con este estudio, auxiliar a lós profesores de La red pública em La elección del material didáctico a ser utilizado em las lecciones Del año escolar subsiguiente y presentar posibilidades para La enseñanza de lós órganos de los sentidos em la perspectiva de La alfabetización científica.

Palabras claves: Enseñanza de las Ciencias. Órganos de los sentidos. Alfabetización científica.

\section{INTRODUÇ̃̃o}

O modelo de escola que temos hoje surgiu de uma demanda da sociedade em promover a dignidade humana nas sociedades desenvolvidas, a partir da instrução dos cidadãos, tanto das classes dominantes como das classes trabalhadoras. Naquela época, a democratização do conhecimento oportunizaria às classes mais baixas a compreensão dos veículos de publicidade e facilitaria que seguissem as instruções e os comandos técnicos de seus superiores no trabalho. (FOUREZ, 1995).

Por outro lado, o saber técnico não é garantia de emancipação sociocultural. Como educadores, identificamos diariamente a dificuldade dos estudantes frente a certos conteúdos e em contrapartida, percebe-se também a satisfação ao perceberem que determinado conhecimento foi apreendido, e ainda mais: que algum assunto da aula chamou sua atenção de modo especial por tratar-se de algo pertencente à sua vivência, o que poderá resultar em mudanças de opiniões, nas suas atitudes e talvez até faça com que consiga transformar a realidade na qual se insere.

Em um mundo cada vez mais atrelado à tecnologia, no qual os jovens fazem uso contínuo de dispositivos eletrônicos, há uma crescente preocupação quanto aos riscos ergonômicos relacionados, principalmente, à visão e audição. Aplicativos e jogos acessados em smartphones, tablets e computadores abusam de uma profusão de cores e sons, cujo uso indiscriminado ou indevido pode trazer danos à saúde. Nesse contexto, uma das autoras deste trabalho se sentiu compelida a descobrir como a visão e a audição, assim como os demais órgãos dos sentidos, estão sendo abordados no livro didático utilizado pelos professores, seja na sala de aula ou como fonte de pesquisa. Atualmente, não se pode mais conceber propostas para o ensino de ciências sem incluir nos currículos componentes que estejam orientados para a busca de aspectos sociais e pessoais dos estudantes. (CHASSOT, 2003).

Segundo Fourez (1995), o conhecimento é uma representação do que é possível fazer e, por conseguinte, representação daquilo que pode ser objeto de uma decisão na sociedade. Sendo assim, a importância do conhecimento não se restringe somente ao desempenho profissional ou técnico, mas constitui-se uma ferramenta na tomada de decisões em qualquer aspecto, desde o planejamento familiar, a escolha de uma profissão ou mesmo decisões cotidianas como qual alimento consumir, qual tipo de exercício físico praticar ou quantas horas diárias de uso das tecnologias digitais é considerada saudável.

O material didático adotado pelos professores nas escolas públicas do país é composto principalmente pela coleção de livros didáticos disponibilizados pelo Ministério da Educação e constituem, juntamente com o conhecimento do professor, a principal fonte de pesquisa norteadora de suas aulas ministradas no ensino fundamental. Por essa razão a escolha de um livro que estimule nos alunos a criticidade e o interesse pela investigação e pelo conhecimento científico são de fundamental importância para que se abordem temas com enfoque nas questões culturais, tecnológicas e sociais do mundo, e desenvolva nos estudantes a alfabetização científica, que poderá lhes introduzir no mundo do conhecimento científico.

O livro didático cumpre um importante papel no processo de ensino e a maneira como os conteúdos são abordados pelo professor pode influenciar no maior ou menor interesse dos alunos e, consequentemente, maior ou menor grau de apropriação do conhecimento. De toda forma, não basta que o professor esteja munido de um livro didático de qualidade, ou seja, é imprescindível que o professor esteja capacitado e que sua atuação promova a aprendizagem significativa de seus alunos. (CARVALHO et al., 2004). 
Diante desse contexto, questionamos: A mera utilização de um livro pelo professor pode induzir nos alunos a certeza de que tal livro é bom e confiável. Mas seria mesmo? Sem profunda análise, não estaria o livro apenas reproduzindo aquilo que há muito já se fazia? Como podemos então descrever este conhecimento, organizar e justificar uma definição para o ingresso dos estudantes no universo do saber científico?

Como professora de Ciências dos anos finais do Ensino Fundamental e usuária de uma das coleções de livros didáticos analisadas neste trabalho, uma das autoras compartilha da preocupação em proporcionar a busca pelo conhecimento utilizando livros e fontes de pesquisa que levem o aluno a pensar, descobrir e refletir sobre os métodos científicos e estabelecer parâmetros próprios para seu crescimento intelectual. (FOUREZ, 1995).

Há no mercado uma diversidade de materiais didáticos que nem sempre atendem às expectativas desta abordagem. $\mathrm{O}$ foco no conteúdo devido à cobrança dos exames de ingresso nas universidades e a cobrança pelo preparo tecnicista imposta pelo mercado de trabalho acabam por fazer com que certos livros não estimulem nos alunos a busca pela origem do conhecimento, pela pesquisa e pelo trabalho dos cientistas, importantes no desenvolvimento do raciocínio, da lógica e do pensamento crítico autônomo. Segundo Bronowski (1977), fugir ao senso comum e adentrar ao mundo da Ciência é libertador.

Assim, problematizamos: A abordagem dos conteúdos referentes aos órgãos dos sentidos, nos livros didáticos de Ciências, pode favorecer o desenvolvimento da alfabetização científica? No âmbito deste trabalho, o objetivo geral foi analisar se os conteúdos referentes aos órgãos dos sentidos, presentes nos livros didáticos de Ciências do Ensino Fundamental, favorecem ao professor elementos norteadores para o desenvolvimento da AC nos estudantes. Foram estabelecidos os seguintes objetivos específicos: a) Descrever as formas pelas quais os livros didáticos abordam o conteúdo de órgãos dos sentidos; b) Analisar a presença ou ausência dos indicadores de alfabetização científica na abordagem do conteúdo de órgãos dos sentidos e c) Problematizar se os livros didáticos podem auxiliar o professor no desenvolvimento da alfabetização científica dos estudantes.

Despertar um olhar científico nos estudantes para que eles tenham condições de fazer uma leitura do mundo onde vivem é função da escola e trabalho do professor, e o livro didático é um grande aliado nesta nobre tarefa. (CHASSOT, 2014).

\section{REFERENCIAL TEÓRICO}

A alfabetização científica e tecnológica emerge no contexto educacional com o desenvolvimento do movimento Ciência Tecnologia e Sociedade, baseado na ideia de permitir que os cidadãos participem das discussões sobre o impacto da ciência e tecnologia na sociedade. (CUNHA, 2017). A Alfabetização Científica (AC) tem sido explorada por diversos pesquisadores da Europa e Estados Unidos, por exemplo, Fourez (1995, 1997), Hurd (1998), Furió et al. (2001), e no Brasil, dedicam-se ao estudo da AC principalmente os pesquisadores Sasseron e Carvalho (2008, 2011) e Chassot (2014). Além da definição da alfabetização científica ser controversa, há ainda a dificuldade linguística na tradução do termo, discutida como alfabetização ou letramento científico (SASSERON; CARVALHO, 2011).

A alfabetização científica abarca a produção e utilização da Ciência nas atividades humanas, e é capaz de gerar transformações com dimensões na democracia, no progresso social e nas necessidades de adaptação do ser humano. (HURD, 1998). Nossa responsabilidade maior no ensinar Ciência é procurar que nossos alunos e alunas se transformem, com o ensino que fazemos, em homens e mulheres mais críticos. (CHASSOT, 2014, p. 77). Para alfabetizar cientificamente os sujeitos é necessário concretizar o ensino de ciências a partir de abordagens metodológicas contextualizadas e interdisciplinares, que possibilitem aos alunos a compreensão da ciência, tecnologia e suas inter-relações com a sociedade. (VIECHENESKI; SILVEIRA, 2012).

Acompanhando o progresso da sociedade, dos meios de comunicação e informação, surge a necessidade de que a população tenha condições de avaliar e participar das decisões que venham a atingir o meio onde vivem e comecem a questionar sobre os impactos da evolução e aplicação da ciência e tecnologia sobre seu entorno e consigam perceber que muitas vezes não atendem à maioria, mas aos interesses dominantes. 
(PINHEIRO; SILVEIRA; BAZZO, 2007). O ser humano, como ser social que é, vive em constante interação com seus pares e a escola é essencial neste processo. A sociedade, que pode ser determinada como um sistema de interações humanas culturalmente padronizadas é uma rede de relacionamentos sociais com símbolos, valores e normas, como também é um sistema de posições e papéis. Inserir-se nesta rede é algo intrínseco da juventude, e a tecnologia vem colaborando para isso nos últimos anos. Quebrar o paradigma de que o homem é coagido a seguir regras exteriores e anteriores ao indivíduo em cada sociedade e fugir à coerção da sociedade em busca de melhoria de vida, da imposição dos seus próprios pensamentos e valores, são propósitos que só podem ser alcançados mediante um processo educacional libertador, que enfoque a Ciência de maneira aplicada às demandas da sociedade. (DURKHEIM, 1978).

O conhecimento científico, se não puder ser adotado pelos cidadãos em suas tarefas cotidianas, só teria validade aos cientistas e desenvolvedores de tecnologias. Entretanto, as aplicações e usos da Ciência não estão limitadas às paredes dos laboratórios de pesquisa ou centros tecnológicos. (FOUREZ, 1995, 1997). Ao contrário, é a partir das salas de aula que os alunos entram em contato com o conhecimento dos conteúdos formais e que a Ciência vem sendo difundida e tomando espaço no desenvolvimento da sociedade, onde dão sentido, conhecem a origem e a razão das coisas e tornam organizado e esquematizado o conhecimento que trazem do seu cotidiano, na interação com a família e em atividades do dia a dia, como escovar dentes, lavar louças, cozinhar, dormir etc.

Alan Chalmers, em seu livro “O que é ciência afinal” (2009), e Jacob Bronowski na obra "O Senso comum da ciência” (1977), discutem sobre o saber popular e o fato científico, mostrando a diferença entre o conhecimento que, mesmo arraigado na cultura e na sociedade, não tem embasamento, sistemática e comprovação. Carl Sagan (1995) discute as visões falsas e verdadeiras do mundo que só a Ciência pode validar, na obra intitulada "O mundo assombrado pelos demônios". A leitura proporciona uma variedade de exemplos que estruturam a educação formal, aquela que deve ser desenvolvida baseada na informação teórica e sistematizada, passível de teste e comprovação. Frases como "As teorias científicas são derivadas de maneira rigorosa da obtenção dos dados da experiência adquiridos por observação e experimentação”, ou "Opiniões ou preferências pessoais e suposições especulativas não tem lugar na ciência” são chamadas por Chalmers (2009, p. 22) como indutivistas ingênuas, e podem ser facilmente confundidas com o senso comum sobre a ciência ao qual se refere Bronowski (1977).

Sagan (1995) considera que a Ciência é o caminho para a liberdade. Através do conhecimento detalhado das questões do mundo que podemos conquistar uma liberdade que nos permita tomar decisões sem a influência de outrem. A preocupação do nosso trabalho jaz exatamente neste ponto, o de buscar o aprofundamento científico, a origem e a raiz das questões estudadas no objetivo de conhecer os problemas cotidianos e fornecer aos alunos meios para solucioná-los.

É na perspectiva apresentada por esses autores e outros que se debruçam sobre a educação científica e tecnológica que temos maior clareza sobre a importância da alfabetização científica. "O conjunto de conhecimentos que facilitariam aos homens e mulheres fazer uma leitura do mundo onde vivem" (CHASSOT, 2014, p. 62), e também disponibilizaria à população os conhecimentos científicos e tecnológicos importantes para a solução de problemas cotidianos e na tomada de decisões das complexas relações entre ciência e sociedade. (FURIÓ et al., 2001).

Na perspectiva da educação escolar, a alfabetização científica pode ser considerada uma via em que o aprendizado de Ciências, mesmo considerando os conhecimentos já estabelecidos na cultura cotidiana do indivíduo, acontece com a aquisição de uma nova cultura, no caso, a cultura científica. (COBERN; AIKENHEAD, 1998). Uma questão que parece ser central para as discussões que se pretende estabelecer é: quais são no mundo de hoje as necessidades de uma alfabetização científica? (CHASSOT, 2014, p. 83). Talvez a preocupação de encontrar uma maneira sustentável de coabitarmos o planeta buscando a paz e a justiça social seja o início do que se pode esperar da transformação proporcionada pela educação.

A velocidade dos avanços científicos e tecnológicos tem imposto, segundo o cientista e escritor Carl Sagan (1995), um descrédito e uma avalanche de ataques sobre a Ciência. Na atualidade, temos nos deparado dia após dia com as "Fake News", notícias falsas disseminadas propositadamente com intuitos variados, mas que confundem a percepção da verdade em diferentes níveis, por exemplo, social, político e religioso. A Ciência não está fora deste panorama, pois têm sido divulgadas uma grande quantidade 
de informações deturpadas, tais como a ineficácia e o risco biológico das vacinas, sobre a cura para o câncer já ter sido descoberta, mas vem sendo mantida em segredo pelas grandes empresas farmacêuticas.

Segundo Fourez (1995), a contextualização, a identificação das demandas sociais, o reconhecimento do saber científico como fato provisório e sujeito a mudanças decorrentes dos avanços das pesquisas e o empoderamento dos cidadãos para a tomada de decisões por meio de informações científicas, são alguns cuidados que devem permear a elaboração do livro didático e justificam a preocupação com o desenvolvimento da alfabetização científica logo nos primeiros anos da educação formal.

Observar e discutir fatos, eventos e fenômenos cotidianos, conhecendo suas causas e possíveis efeitos, empodera o ser humano para que seja o protagonista dos seus atos e possa agir de acordo com as conclusões que ele mesmo formulou, fundamentadas na Ciência. Este seria o ponto que torna a alfabetização, o letramento ou a enculturação científica peça chave no desenvolvimento completo dos jovens de hoje e cidadãos do amanhã. Sasseron e Carvalho (2011) propõem uma concepção de alfabetização científica que pode ser vista como um processo de "enculturação científica” dos estudantes, no qual esperaríamos promover condições para que os alunos fossem inseridos em mais uma cultura, a cultura científica.

Sasseron e Carvalho (2008) propuseram indicadores de alfabetização científica com o objetivo principal de mostrar algumas habilidades que devem ser trabalhadas quando se deseja colocar a AC em processo de construção entre os estudantes. Estes indicadores mostram se o caminho da aprendizagem está sendo trilhado com base nos Eixos Estruturantes da Alfabetização Científica, que visam a compreensão básica de termos, conhecimentos e conceitos científicos fundamentais. A importância deles reside na necessidade exigida em nossa sociedade de se compreender conceitos-chave como forma de poder entender até mesmo pequenas informações e situações do dia-a-dia; a compreensão da natureza da ciência e dos fatores éticos e políticos que circundam sua prática, pois, em nosso cotidiano.

Durante o percurso investigativo, verificamos que apenas três indicadores estabelecidos por Sasseron e Carvalho (2008) mostraram-se adequados para a análise do livro didático. É importante destacar que esses indicadores foram propostos para analisar "evidências sobre como os estudantes trabalham durante a investigação de um problema e a discussão de temas das ciências fornecendo elementos para se dizer que a Alfabetização Científica está em processo de desenvolvimento para eles.” (SASSERON, 2008, p. 80). O conjunto desses indicadores permite a análise das interações entre os alunos durante as aulas e atividades, porém, consideramos que os indicadores referentes à seriação, organização e classificação de conteúdos são pertinentes para analisar os conteúdos referentes aos órgãos dos sentidos presentes nos livros didáticos de Ciências. Avaliamos que estes três indicadores promovem a sistematização do conteúdo e seu respaldo técnico, além de subsidiarem o professor no planejamento de suas aulas e atividades e, portanto, nos pareceram adequados para a análise. No Quadro 1, apresentamos os três indicadores, propostos por Sasseron e Carvalho (2008), utilizados como critérios de análise neste trabalho:

Quadro 1 - Indicadores de AC

\begin{tabular}{|c|c|}
\hline INDICADOR & DETALHAMENTO \\
\hline $\begin{array}{c}\text { Seriação de } \\
\text { Informações }\end{array}$ & $\begin{array}{r}\text { Está ligada ao estabelecimento de bases para a ação investigativa. Não prevê, } \\
\text { necessariamente, uma ordem que deva ser estabelecida para as informações: pode ser uma } \\
\text { lista ou uma relação dos dados trabalhados ou com os quais se vá trabalhar. }\end{array}$ \\
\hline $\begin{array}{c}\text { Organização de } \\
\text { Informações }\end{array}$ & $\begin{array}{c}\text { Surge quando se procura preparar os dados existentes sobre o problema investigado. Este } \\
\text { indicador pode ser encontrado durante o arranjo das informações novas ou já elencadas } \\
\text { anteriormente e ocorre tanto no início da proposição de um tema quanto na retomada de } \\
\text { uma questão, quando ideias são relembradas. }\end{array}$ \\
\hline $\begin{array}{c}\text { Classificação de } \\
\text { Informações }\end{array}$ & $\begin{array}{c}\text { Aparece quando se buscam estabelecer características para os dados obtidos. Por vezes, } \\
\text { ao se classificar as informações, elas podem ser apresentadas conforme uma hierarquia, } \\
\text { mas o aparecimento desta hierarquia não é condição sinequa non para a classificação de } \\
\text { informações. Caracteriza-se por ser um indicador voltado para a ordenação dos elementos } \\
\text { com os quais se trabalha. }\end{array}$ \\
\hline
\end{tabular}

Fonte: Adaptado de Sasseron e Carvalho (2008). 


\section{PERCURSO METODOLÓGICO}

A pesquisa qualitativa apresenta-se como uma possibilidade para se estudar os fenômenos que envolvem os seres humanos e suas intrincadas relações sociais, estabelecidas em diversos ambientes (GODOY, 1995), o que em nosso trabalho configura-se no livro didático de Ciências. Partindo de questões amplas que vão se aclarando no decorrer da investigação, o estudo qualitativo pode ser conduzido através de diferentes caminhos.

É nessa perspectiva que se insere a opção metodológica deste trabalho, no qual analisamos qualitativamente os textos dos livros didáticos. O objeto de estudo foram quatro coleções de livros que fazem parte do material didático de Ciências da Natureza, disponível para os professores da rede pública municipal de Blumenau, todos aprovados pelo Programa Nacional do Livro Didático 2017-2019 (PNLD) do Governo Federal. Entre as coleções disponíveis, foram preliminarmente selecionados os títulos listados no Quadro 2, todos referentes ao oitavo ano do Ensino Fundamental.

Quadro 2 - Livros didáticos selecionados para análise

\begin{tabular}{|c|c|c|}
\hline Coleção & Autores & Editora e ano de publicação \\
\hline Projeto Araribá & Maíra Rosa Carnevalle & Moderna (2014) \\
\hline Apoema & $\begin{array}{c}\text { Ana Maria Pereira, Margarida } \\
\text { Santana, Mônica Waldheim }\end{array}$ & do Brasil (2015) \\
\hline Teláris & Fernando Gewandsznajder & Ática (2013) \\
\hline Investigar e Conhecer & Sônia Lopes & Saraiva (2015) \\
\hline
\end{tabular}

Fonte: Elaborado pela autora.

Para a análise do corpus e reconhecimento dos indicadores de alfabetização científica na abordagem dos órgãos dos sentidos, realizamos uma leitura preliminar para a seleção dos trechos nos quais os conteúdos relacionados aos órgãos dos sentidos são tratados. Posteriormente foi realizada uma segunda leitura dos trechos selecionados e de seus componentes, tais como gravuras, esquemas, quadros, gráficos, etc., a fim de organizar o corpus de análise de acordo com os indicadores apresentados no Quadro 1. Uma vez localizados os indicadores no texto, procedeu-se à análise qualitativa.

\section{RESULTADOS E DISCUSSÃO}

Tomando por base a visão do Programa Nacional do Livro Didático, que considera que através de produtivo processo de ensino e aprendizagem, em que tanto o estudante quanto o professor estão constantemente reconstruindo o conhecimento e se aproximando da linguagem científica, o livro didático aparece como um instrumento de apoio, de estruturação de conceitos e de inspiração para investigação de fenômenos interessantes, sejam eles de ocorrência cotidiana ou não. Portanto, o livro de Ciências não deve estar a serviço de um ensino focado na informação, na memorização e em temas e práticas descontextualizadas, mas sim a serviço de um ensino ativo, inovador, baseado em processos de investigação, na experimentação, no registro claro e útil, na troca e construção coletiva e na comunicação. (BRASIL, 2015). Em vista disso, compilamos o que foi apurado sobre cada indicador, conforme segue:

\section{INDICADORES DE SERIAÇÃO, ORGANIZAÇ̃̃̃O E CLASSIFICAÇÃO DE CONTEÚDOS}

Originalmente separados em três indicadores distintos, os três tópicos foram aglutinados em um só indicador, por considerarmos que tratam de ações muito próximas no que compete à escrita do conteúdo. Estão presentes quando o texto busca estabelecer relações para a ação investigativa a partir das características dos dados obtidos. Por vezes, ao se classificar as informações, elas podem ser apresentadas conforme uma hierarquia, mas o aparecimento desta hierarquia não é condição sinequa non para a classificação de informações. Este indicador pode ser encontrado durante o arranjo das informações novas ou 
já elencadas anteriormente e ocorre tanto no início da proposição de um tema quanto na retomada de uma questão, quando ideias são relembradas. Caracteriza-se por ser um indicador voltado para a ordenação dos elementos com os quais se trabalha.

\section{COLEÇ̃̃O PROJETO ARARIBÁ}

O conteúdo de órgãos dos sentidos está representado no livro pesquisado de maneira clara e objetiva, sendo o texto corrido enriquecido com gravuras representando as estruturas físicas e os órgãos que compõem cada sentido, fotos, esquemas que demonstrem a formação da imagem, do som (Figura 01), ou o percurso das partículas olfativas pelo nariz (Figura 02) e informações complementares que extravasam o conhecimento técnico, e mostram aplicação direta do sentido do paladar, trazendo o sabor umami como uma nova percepção do sabor, muito explorada nos atuais e populares shows midiáticos sobre gastronomia (Figura 03).

Figura 01 - Esquema de formação do som no ouvido humano

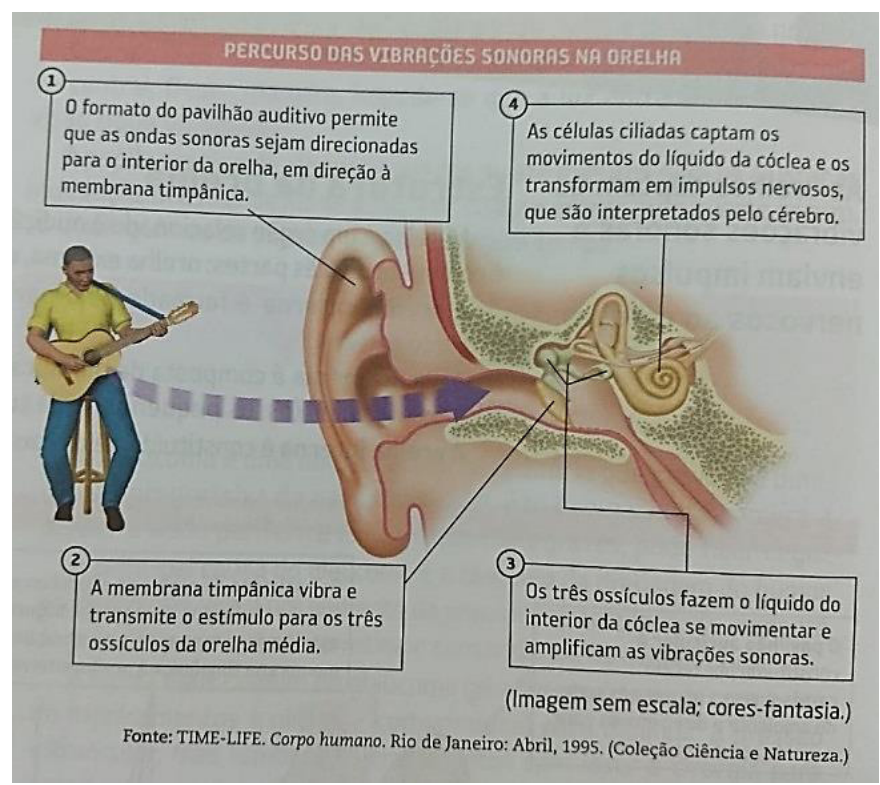

Figura 02 - Percurso das partículas olfativas pelo nariz

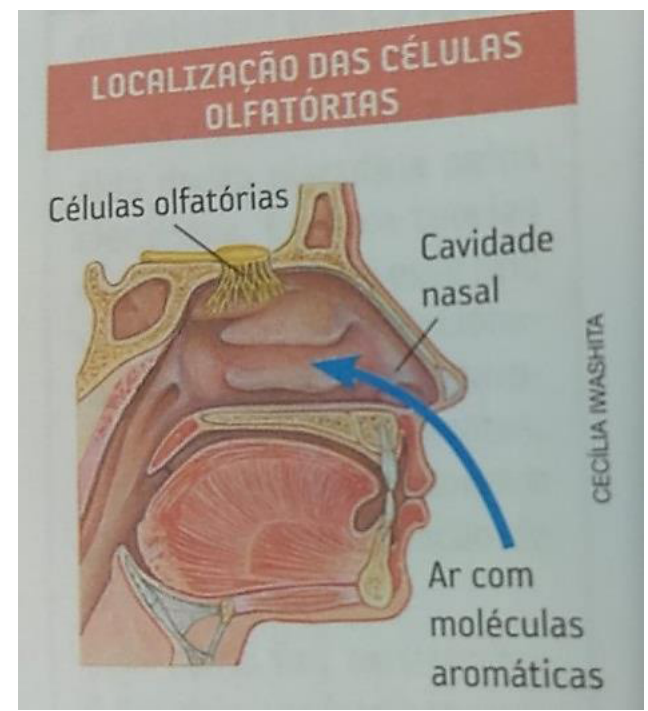

Figura 03 - Sabor umami

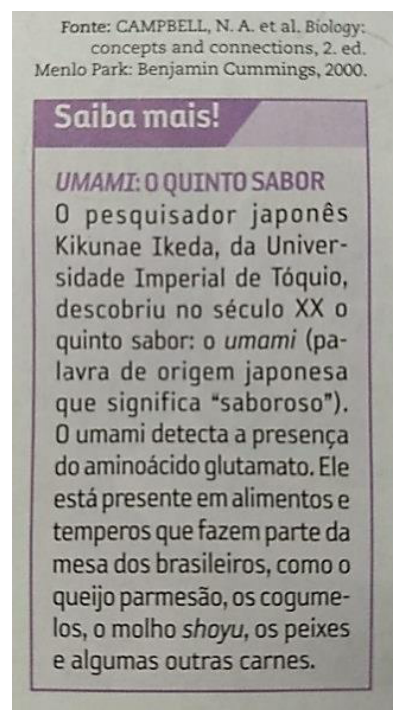

Fonte: Coleção Projeto Araribá Ciências 8ª ano, 2014. 
Percebe-se no texto uma preocupação com a organização das informações e o conteúdo, dispondo-as de maneira ordenada, com títulos e subtítulos condizentes com o teor do texto e mostrando por vezes os significados de vocábulos específicos da anatomia e fisiologia humana, ou simplesmente incomuns (Figura 04). Cada conjunto sensorial é tratado isoladamente, relacionando-se os órgãos ou tecidos envolvidos, o mecanismo de ação e a importância para o organismo.

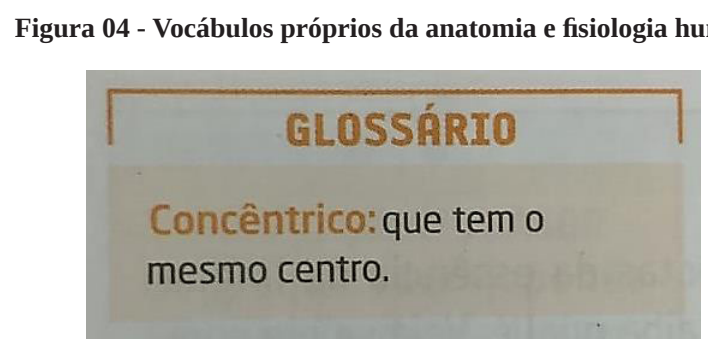

Fonte: Coleção Projeto Araribá Ciências 8ª ano, 2014.

As questões de atualidade, curiosidades e informações adicionais encontram-se dispostas em caixas de texto coloridas que chamam a atenção para o estabelecimento de relações diretas com o conhecimento apresentado no texto, por exemplo, reflexões acerca de quais sentidos são mais utilizados na atuação profissional (Figura 05), nas disfunções oculares (Figura 06), no funcionamento das lentes corretivas (Figura 07) e um comparativo da intensidade de ruído em atividades cotidianas (Figura 08).

Figura 05 - Sentidos mais utilizados pelos trabalhadores das indústrias

\section{De olho no tema}

Algumas indústrias de alimento contratam degustadores, responsáveis pelo controle de qualidade de seus produtos. Eles analisam a consistência, 0 aroma e 0 sabor dos alimentos para manter um padrão em toda a produção.

- Quais são os sentidosusados por essas pessoas durante o trabalho?
Figura 06 - Disfunções oculares

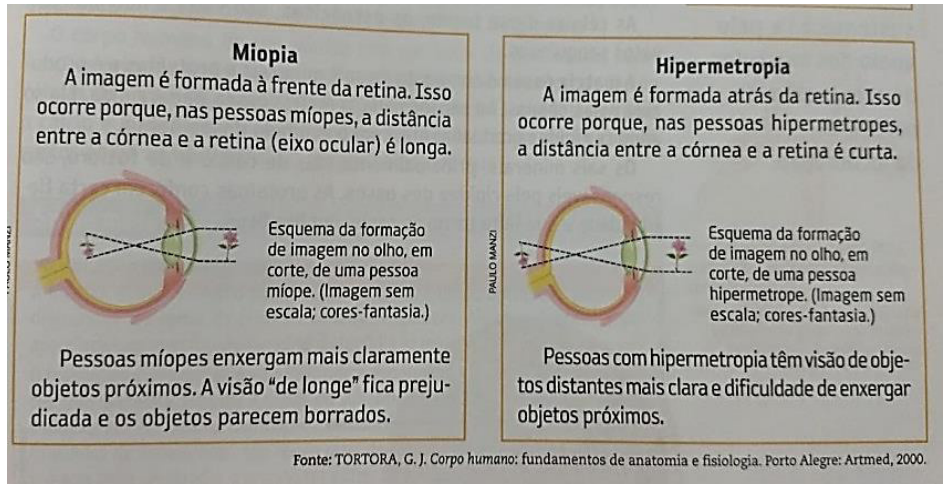

189

Fonte: Coleção Projeto Araribá Ciências 8º ano, 2014.

Figura 07 - Funcionamento das lentes corretivas

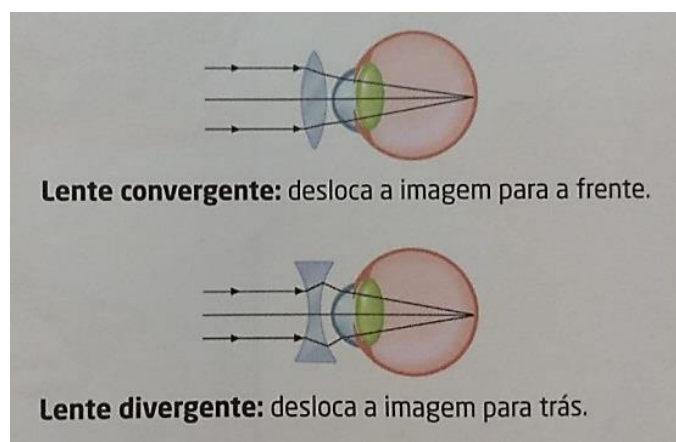

Figura 08 - comparativo da intensidade de ruído em atividades cotidianas

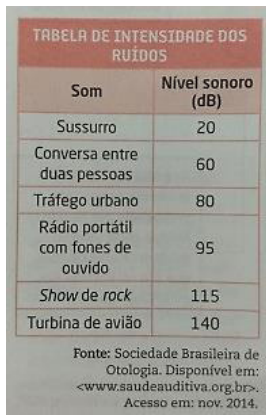

Fonte: Coleção Projeto Araribá Ciências 8º ano, 2014. 
As gravuras apresentadas exemplificam os casos relatados e demonstram de maneira fidedigna o conteúdo descrito. As imagens tornam-se, na maior parte das vezes, uma excelente maneira de contextualização e aproximação com a realidade. Percebe-se, quando uma das autoras aborda o conteúdo de órgãos dos sentidos em sala de aula, uma atenção especial dos seus alunos em relação aos perigos do mau uso dos dispositivos eletrônicos. Esta é uma demanda atual que pode ser abordada nas aulas de Ciências, utilizando os elementos apresentados e discutindo quais alternativas são menos prejudiciais ao organismo para que a utilização de tablets, celulares e fones de ouvido seja mais consciente. Desta forma, a explanação de informações com fundamento científico pode fazer a diferença na escolha dos estudantes a respeito do uso dos dispositivos eletrônicos, e da quantidade de tempo dispendido a eles. Possuir dados que os guiem na tomada de decisões rumo a uma melhor qualidade de vida pode ser considerado um dos objetivos da AC.

\section{APOEMA}

O texto expõe o conteúdo de maneira acessível ao estudante, explicando os pormenores a respeito de cada órgão e função que desempenha (Figura 09) no organismo humano de modo claro, conciso e com linguagem acessível aos estudantes do ensino fundamental. Também apresenta informações atuais, como as tecnologias assistivas, com aplicação direta para pessoas com deficiência em algum dos sentidos (Figura 10). Ilustrações do tipo desenho que representam os órgãos, fotos e diagramas enriquecem o aprendizado e facilitam a compreensão, pois o jovem na atualidade está fortemente conectado a diversas mídias, o que torna o texto mais atrativo a esta faixa etária, uma vez que o livro didático compete com os dispositivos eletrônicos e com a mídia pela atenção dos jovens.

Figura 09 - Detalhes a respeito de cada órgão e função

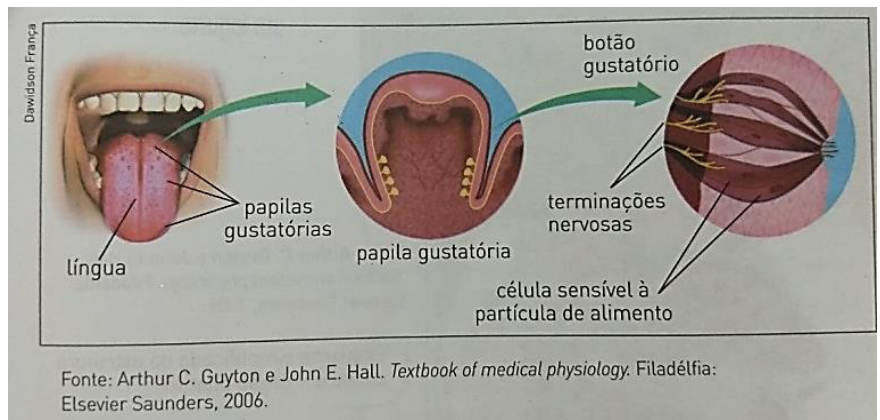

Fonte: Coleção Apoema Ciências 8ªno, 2015.

Figura 10 - Tecnologias assistivas

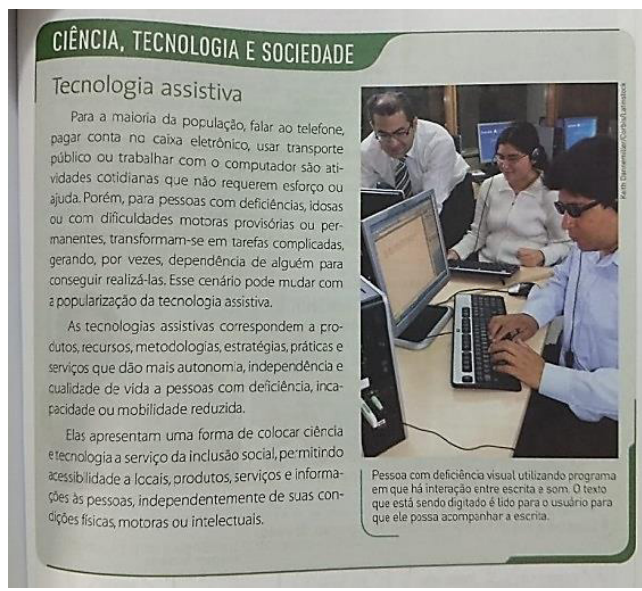

Fonte: Coleção Apoema Ciências 8 ano, 2015. 
É possível analisar um desenho esquemático que mostra a ligação de cada sentido com a região cerebral relacionada (Figura 11), e assim compreender onde se processa a interpretação sensorial na mente humana. Desenhos esquemáticos e ilustrativos expõem a formação da visão e tornam clara a maneira como a imagem é formada no olho humano, assim como a dilatação e a contração da pupila (Figura 12) são possíveis de serem comparadas através de fotos do olho nas duas situações.

\section{Figura 11 - Ligação de cada sentido com a região cerebral}

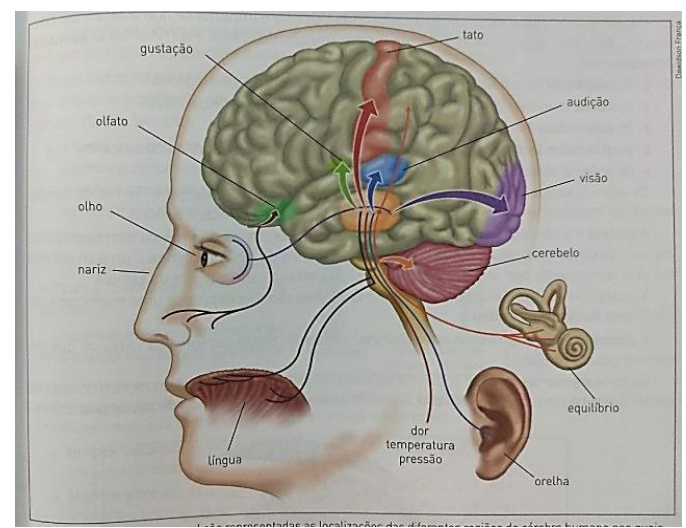

Fonte: Coleção Apoema Ciências $8^{\circ}$ ano, 2015.

Figura 12 - Dilatação e a contração da pupila

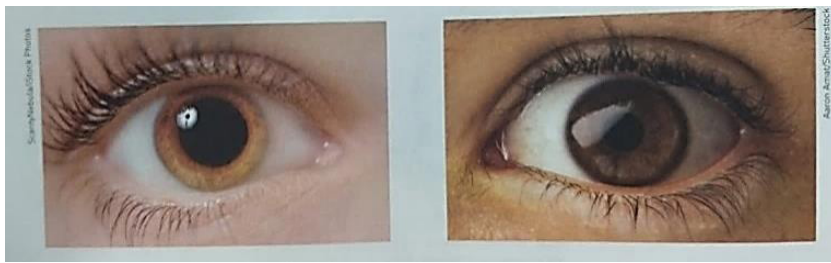

Fonte: Coleção Apoema Ciências 8º ano, 2015.

O tema olfato, e sua importância, é trazido à reflexão através de uma foto comentada da utilização de um cão farejador na busca de vítimas em desastres (Figura 13). Tais exemplos reforçam ao estudante a importância que os sentidos apresentam, e ressalta que é mister estudá-los. O livro apresenta as demandas, e traz as soluções que podem ser adotadas nas diferentes situações, como é o caso do cão farejador, onde há necessidade da utilização de um sentido específico do corpo, o olfato, no caso do cão, onde outros sentidos de visão e audição que seriam os mais comuns na busca por pessoas desaparecidas não surtem efeito. Destacamos também a imagem de um pedaço de queijo sendo aproximado da boca, momento onde é possível a percepção pelo sentido do olfato e do paladar quase simultânea, e que podem demonstrar os mesmo padrões ou despertar surpresas olfato-gustativas (Figura 14).

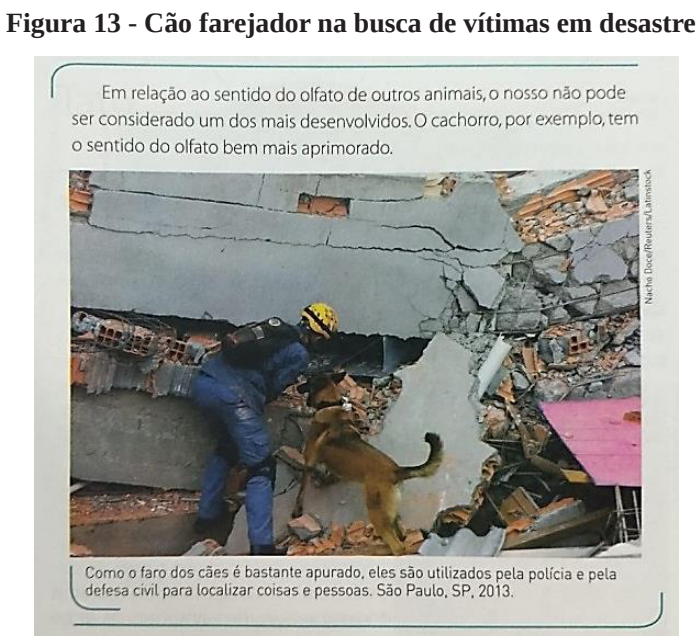

Fonte: Coleção Apoema Ciências 8º ano, 2015. 
Figura 14 - Pedaço de queijo sendo aproximado da boca

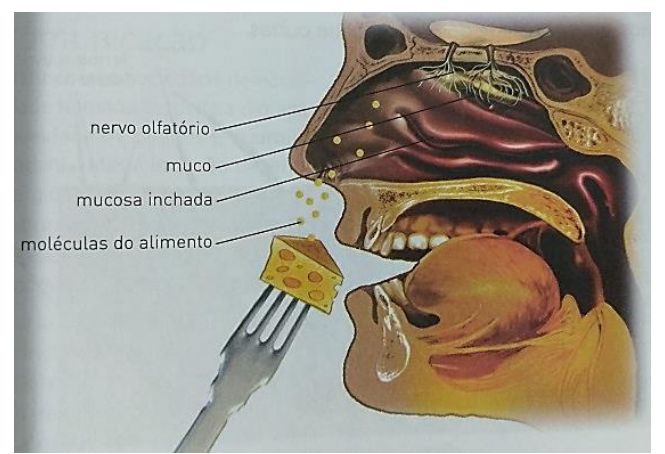

Fonte: Coleção Apoema Ciências $8^{\circ}$ ano, 2015.

\section{TELÁRIS}

A exposição do conteúdo é realizada de maneira clara, detalhando os principais aspectos de cada órgão, e peculiaridades de cada sentido (Figura 15). Órgãos como olho, orelha, nariz e pele são especificados nas gravuras com detalhes esclarecedores. O texto inicia com questionamentos que estimulam a realização de pesquisas (Figura 16), possibilitando ao professor atuar como mediador de assimilação do conteúdo. O docente traz para a discussão sua experiência de vida e de sala de aula, e enriquece o debate acerca dos assuntos trazidas pelo livro.

Figura 15 - Principais aspectos de cada órgão

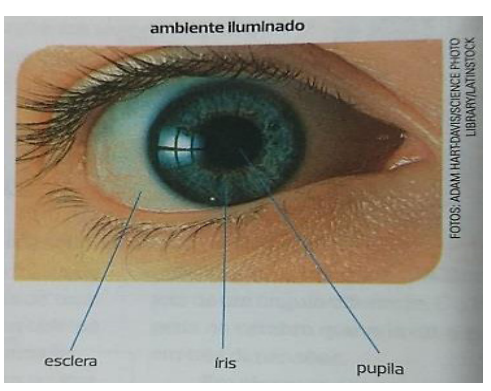

Figura 16 - Questionamentos que inspiram a pesquisa

Você sabe qual é a função da iris, da lente (cristalino) e da retina? Sabe que fenômenos ocorrem quando o som atinge a orelha? E que sentidos dependem principalmente do nariz, da língua e da pele?

As ilustrações são dos tipos desenho, diagramas e fotos e contribuem para a compreensão do texto corrido e ilustram com exemplos e sugestões de experimentos (Figura 17) ou relatos que aproximam o tema à realidade do estudante para trazer clareza à compreensão do conteúdo. Além disso, salientam de forma clara as minúcias de cada órgão, o que auxilia na compreensão de sua fisiologia.

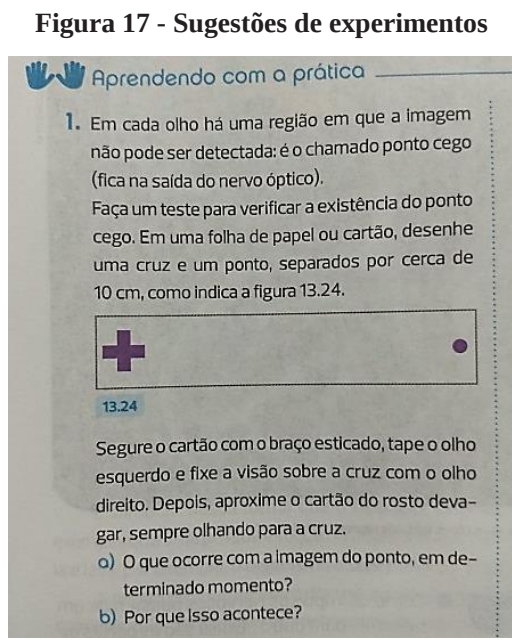

Fonte: Coleção Teláris Ciências 8ª ano, 2013. 
Atualidades e informações complementares são apresentadas em abundância por meio de caixas de texto, notas e gravuras auxiliares, que buscam aproximar os conhecimentos do senso comum do conhecimento científico, como é o caso da imagem que demonstra a visão do míope comparada à visão de quem não possui disfunção visual. É possível compreender, pelo exemplo das fotos, como é o cotidiano de uma pessoa com miopia, e entender suas dificuldades e a necessidade das lentes corretivas (Figura 18).

Figura 18 - Cotidiano de uma pessoa com miopia.

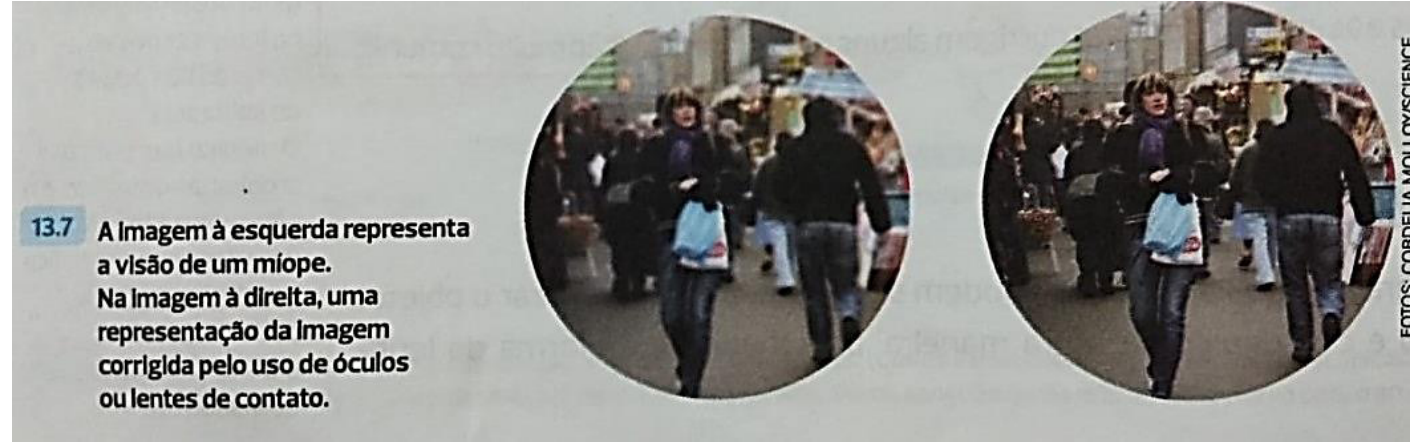

Fonte: Coleção Teláris Ciências 8ªno, 2013.

O Braille, fundamental para os cegos aprenderem a ler e escrever, é ilustrada por meio da figura 19. O professor pode relacionar a imagem às marcações presentes nas teclas dos elevadores mais novos e em algumas embalagens de alimentos. A aproximação dos estudantes com verbetes utilizados no meio científico é realizada por meio de um pequeno glossário distribuído ao longo do texto para auxiliar na compreensão e reconhecimento do conhecimento científico exposto pelo livro (Figura 20).

Figura 19 - Escrita Braille

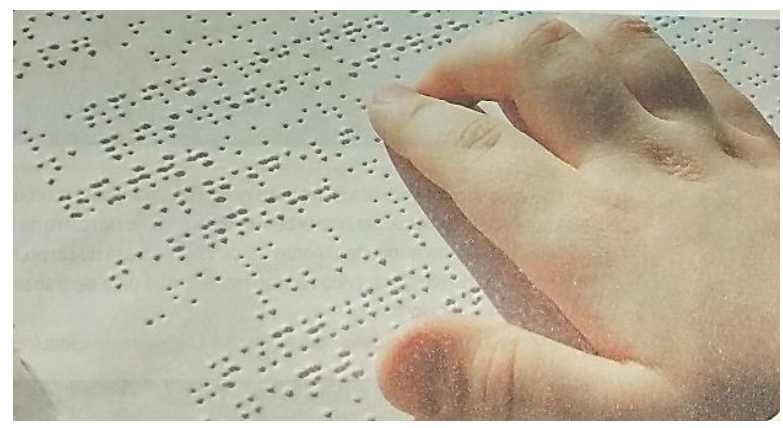

Figura 20 - Verbetes próprios da linguagem científica

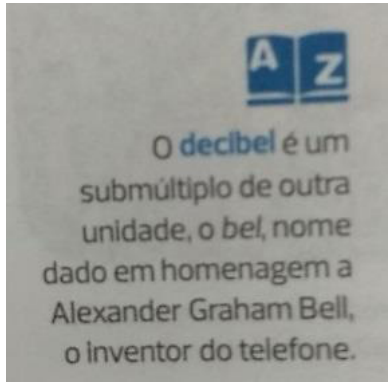

Fonte: Coleção Teláris Ciências 8º ano, 2013.

\section{INVESTIGARE CONHECER}

Quando comparado às demais coleções de livros didáticos, verificou-se maior facilidade de leitura nesta coleção, pois o texto é apresentado de maneira clara e agradável. Fotos e desenhos contribuem para a compreensão do conteúdo, bem como algumas notas da atualidade com resultados de pesquisas (Figura 21), reconhecimento do conteúdo como fato científico ou mesmo novidades que aparecem na mídia em geral, e que fornecem informações complementares de grande valia. Cenas do cotidiano com pessoas sentindo o aroma agradável da comida, ou utilizando de maneira otimizada a luz para a leitura de um bom livro (Figura 22) apresentam cenas próximas das vivências cotidianas dos estudantes. 
Figura 21 - Resultados de pesquisas

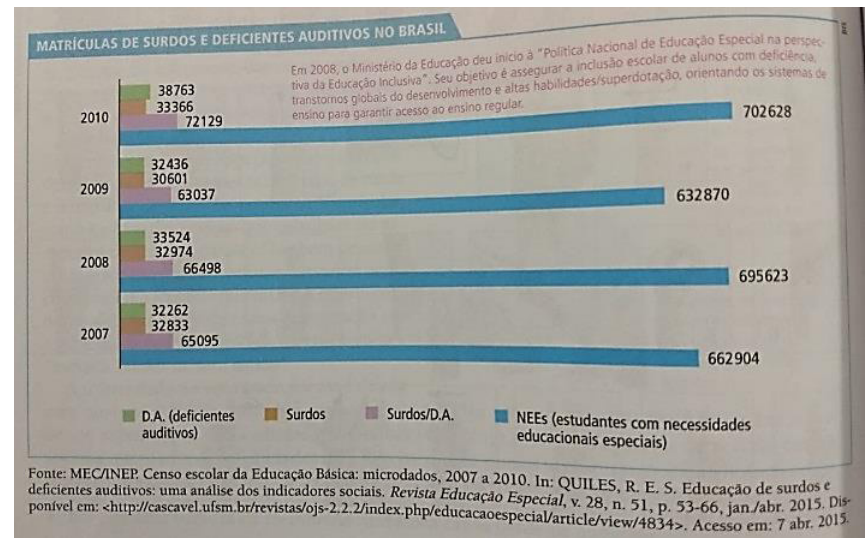

Figura 22 - Utilização otimizada da luz para leitura

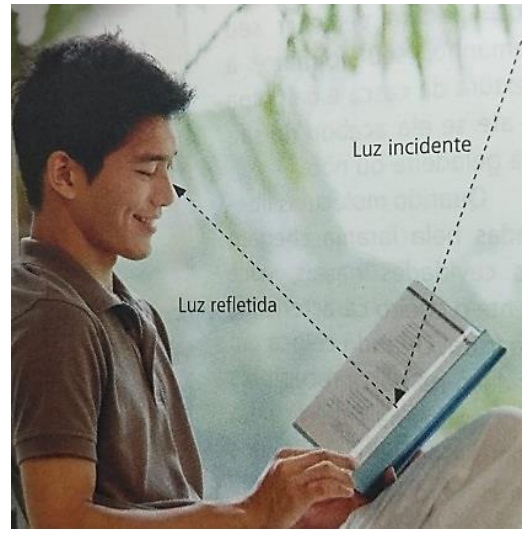

Fonte: Coleção Investigar e Conhecer Ciências 8ªno, 2015.

O alfabeto em Libras é apresentado por meio de sinais com as mãos (Figura 23) e pode favorecer ao professor a importante discussão sobre a inclusão de surdos. A Libras é reconhecida como meio legal de expressão e comunicação e que deve ser institucionalizada, conforme Lei 10.436 de 12 de abril de 2002 e regulamentada pelo Decreto no 5.626/2005.

\section{Figura 23 - Alfabeto em Libras}

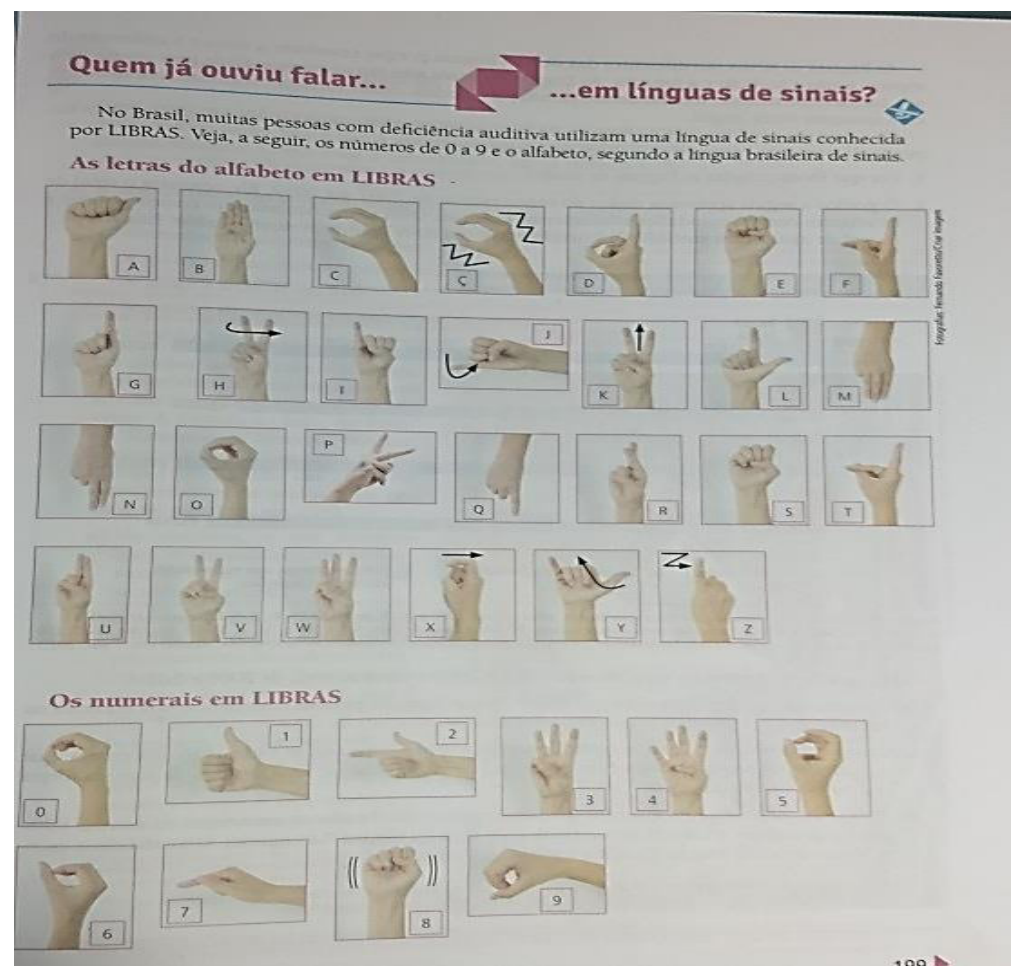

Fonte: Coleção Investigar e Conhecer Ciências 8º ano, 2015.

Atividades investigativas são propostas a fim de corroborar a aprendizagem e reforçar a assimilação do conteúdo, como demonstrado na Figura 24. São trazidos exemplos do cotidiano relacionados aos temas abordados para que o estudante reconheça e compreenda fenômenos que vivencia individual ou coletivamente com seus familiares, vizinhos de bairro, amigos e colegas da escola. 
Figura 24 - proposição de atividades investigativas

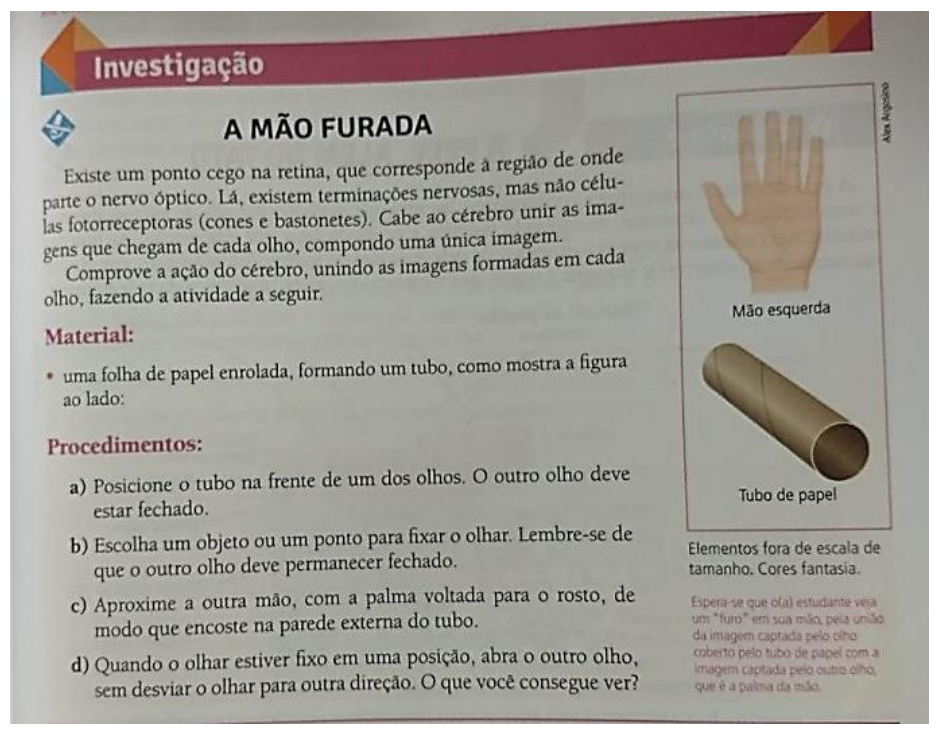

Fonte: Coleção Investigar e Conhecer Ciências 8º ano, 2015.

Os cuidados com o corpo e os sentidos são discutidos em um texto que aponta os perigos da exposição prolongada a sons altos (Figura 25) e pode levar o professor a debater com os alunos sobre os riscos aos quais estão expostos no dia a dia. O texto estimula a aprendizagem e torna a investigação parte do processo de apropriação do conhecimento de maneira profícua, trazendo o saber científico e aproximando à realidade social dos estudantes, utilizando ferramentas que chamam a atenção como uma ilusão visual (Figura 26), onde a imagem tenta proporcionar uma sensação de movimento e o professor pode trabalhar os fatos científicos que levam a tal percepção.

Figura 25 - Perigos da exposição ao som

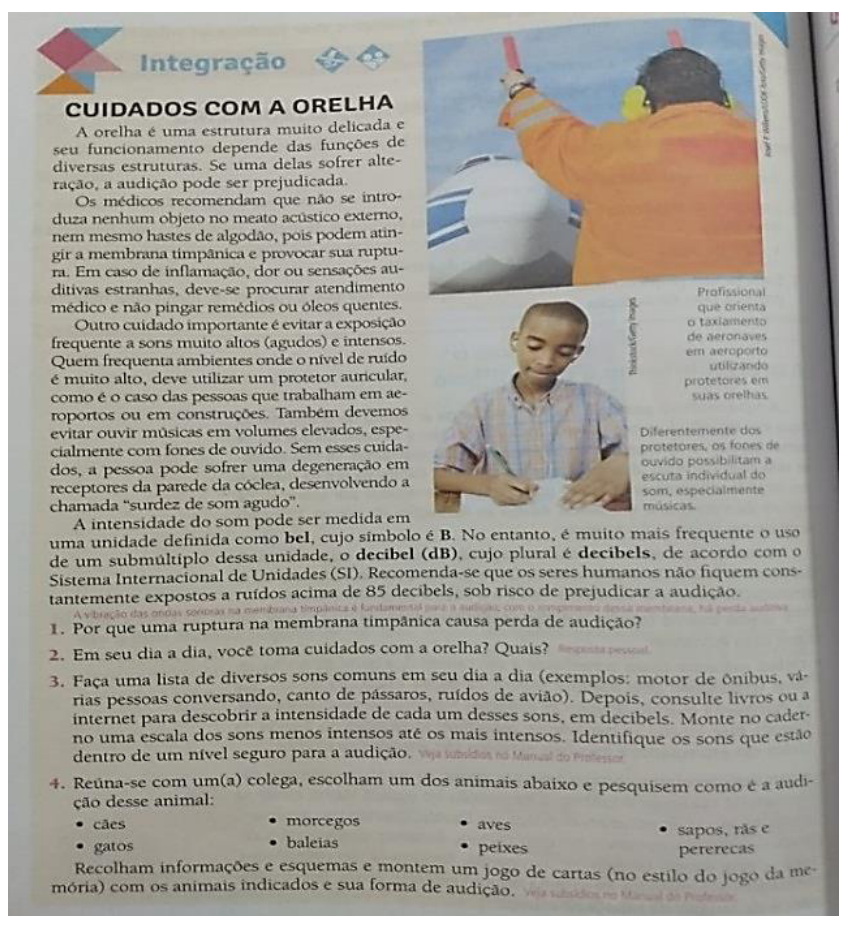

Fonte: Coleção Investigar e Conhecer Ciências 8º ano, 2015. 
Figura 26 - Ilusão visual

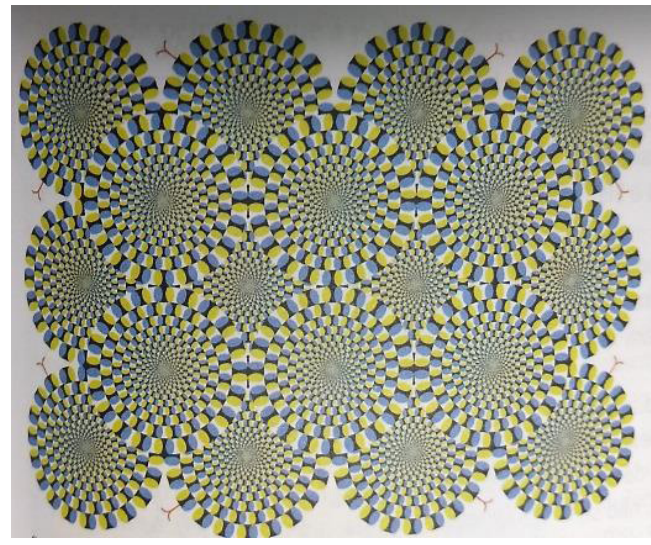

Fonte: Coleção Investigar e Conhecer Ciências 8ªno, 2015.

Por meio da identificação dos indicadores de alfabetização científica nos livros disponibilizados pela rede pública, o professor encontra auxílio para realizar a escolha da coleção a ser utilizada no ano letivo, uma vez que seu intuito educacional seja desenvolver a alfabetização científica. "Para alfabetizar cientificamente os sujeitos, faz-se necessário efetivar um ensino de ciências a partir de uma abordagem interdisciplinar, que contemple as interações entre ciência, tecnologia e sociedade.” (VIECHENESKI e SILVEIRA, 2012).

\section{CONSIDERAÇÕES FINAIS}

O conteúdo das quatro coleções de livros didáticos pesquisadas demonstrou a presença de imagens, figuras e informações que podem favorecer o desenvolvimento da alfabetização científica. Avaliamos os títulos pesquisados contribuem para a construção de um conhecimento pautado no saber científico e que apresenta as preocupações e conhecimentos práticos do cotidiano relacionados à sistematização da Ciência. Entretanto, a conformidade com os indicadores não garante que o livro didático, por si só, desenvolva a Alfabetização Científica nos estudantes.

Percebe-se que os trechos dos livros didáticos analisados proporcionam aos estudantes, com a mediação do professor, as informações necessárias para que se apropriem do conhecimento científico com vistas ao seu pleno desenvolvimento, no intuito de se tornarem cidadãos críticos. O material estudado propõe-se a auxiliar o estudante em sua relação com a sociedade e seu papel como cidadão e, desta forma, está consonante com a perspectiva da alfabetização científica proposta por Fourez (1997), que defende que o conhecimento abre portas e indica caminhos, auxilia na tomada de decisões, no equilíbrio ideológico e influencia na construção da auto-imagem, principalmente no conteúdo enfocado neste trabalho, os órgãos dos sentidos.

A análise dos conteúdos relacionados aos órgãos dos sentidos nos livros didáticos de Ciências do oitavo ano mostrou-se satisfatória e pode auxiliar no desenvolvimento da alfabetização científica nos estudantes. Alguns elementos trazidos nas análises de cada título demonstram que os autores tiveram a preocupação de identificar as demandas da sociedade e relacioná-las ao conteúdo. Este é um processo que exige contínua atualização, visto que as necessidades e interesses dos jovens vão se moldando às mudanças na sociedade e aos avanços da tecnologia.

A discussão dos fatos e eventos do cotidiano sob a perspectiva da Ciência é a maneira pela qual o ser humano tornar-se-á apto a compreender o mundo sob seus próprios critérios, empoderando-no com conhecimentos que sirvam de base na tomada de decisões para a transformação da realidade em busca de uma melhor qualidade de vida. O livro didático repleto de elementos que desenvolvam a AC, que estimule a investigação e aprimore o senso crítico é uma importante ferramenta nas mãos de um professor que deseja educar estudantes para um mundo melhor, mais evoluído, mais crítico, mais humano e mais justo. Lançando mão do livro didático, com o planejamento e o fazer pedagógico que estimule a investigação, 
a crítica e a transformação em nossos alunos, será possível colher frutos de nossas semeaduras para fazermos juntos a construção da cidadania, fazendo que mulheres e homens desenvolvam a alfabetização científica. (CHASSOT, 2014).

Espera-se que o estudante, ao conhecer as patologias de ordem ocular, auditiva, postural, etc. que podem ser desenvolvidas com o mau uso ou uso excessivo de dispositivos eletrônicos, tem à mão o poder de decisão sobre como ou por quanto tempo manusear tais aparelhos para que não prejudique sua saúde física e mental. Ao conhecer mais sobre os distúrbios oculares, o aluno tem informações para perceber se está acometido por algum distúrbio e assim procurar um profissional da saúde e até mesmo qual profissional procurar em casos de necessidade. O jovem esclarecido vai ter condições de discernir entre qual profissional consultar em caso de necessidade.

\section{REFERÊNCIAS}

BRASIL. Decreto $n^{0}$ 5.626, de 22 de dezembro de 2005. Regulamenta a Lei ${ }^{\circ} 10.436$, de 24 de abril de 2002, que dispõe sobre a Língua Brasileira de Sinais - LIBRAS, e o art. 18 da Lei no 10.098, de 19 de dezembro de 2000. Brasília, DF: Câmara dos Deputados, 2005. Disponível em: http://www2.camara. leg.br/legin/fed/decret/2005/decreto-5626-22-dezembro-2005-539842-publicacaooriginal-39399-pe. html. Acesso em: 27 fev. 2019.

BRASIL. Guia de livros didáticos: PNLD 2016: Ciências: ensino fundamental anos iniciais. Brasília: Ministério da Educação; Secretaria de Educação Básica, 2015.

BRONOWSKI, J. O senso comum da ciência. São Paulo: Itatiaia, 1977.

CARVALHO, A. M. P. (org.). Ensino de ciências: unindo pesquisa à prática. São Paulo: Thomson, 2004.

CHALMERS, A. F. O que é ciência afinal. São Paulo: Brasiliense, 2009.

CHASSOT, A. Alfabetização científica: questões e desafios para a educação.Ijuí: Unijuí, 2014.

CHASSOT, A. Alfabetização científica: uma possibilidade para a inclusão social. Revista Brasileira de Educação, Rio de Janeiro, s./v., n. 22, p. 89-100, jan./abr.2003.

COBERN, W. W.; AIKENHEAD, G. S. Cultural aspects of learning science. Part one. Norwell: Kluwer Academic Publishers, 1998.

CUNHA, R. B. Alfabetização científica ou letramento científico: interesses envolvidos nas interpretações da noção de scientific literacy. Revista Brasileira de Educação, Rio de Janeiro, v. 22, n. 68, p. 169-186, mar. 2017.

DURKHEIM, E. Educação e sociologia. Melhoramentos: São Paulo, 1978.

FOUREZ, G. Alfabetización científica y tecnológica: acerca de las finalidades de la enseñanza de las ciencias. Buenos Aires: Colihue, 1997.

FOUREZ, G. A construção das ciências: introdução à filosofia e à ética da ciência. São Paulo: UNESP, 1995.

FURIÓ, C.; VILCHES, A.; GUISASOLA, J.; ROMO, V. Finalidades de la enseñanza de las ciencias em la secundaria obrigatória. Alfabetización científica o propedéutica? Enseñanza de las ciencias, Barcelona, v. 19, n. 3, p. 365-376, set./dez. 2001.

HURD, P. D. Scientific literacy: new minds for a changing world. Science Education, v. 82, n. 3, 407416, may/june 1998.

PINHEIRO, N. A. M.; SILVEIRA, R. M. C. F.; BAZZO, W. A. Ciência, tecnologia e sociedade: a relevância do enfoque CTS para o contexto do ensino médio. Revista Ciência e Educação, Bauru, v. 13, n. 1, p. 71-84, jan./abr. 2007. 
SAGAN, C. O mundo assombrado pelos demônios. São Paulo: Companhia das letras, 1995.

SASSERON, L. H. Alfabetização científica no ensino fundamental: estrutura e indicadores deste processo em sala de aula. 2008, 261 f. Tese (Doutorado em Educação) - Faculdade de Educação, USP, São Paulo, 2008.

SASSERON, L. H.; CARVALHO, A. M. P. Alfabetização científica: uma revisão bibliográfica. Investigações em Ensino de Ciências, Porto Alegre, v. 16, n. 1, p. 59-77, jan./abr. 2011.

SASSERON, L. H.; CARVALHO, A. M. P. Almejando a alfabetização científica no ensino fundamental: a proposição e a procura de indicadores do processo. Investigações em Ensino de Ciências, Porto Alegre, v. 13, n. 3, p. 333-352, set./dez. 2008. Disponível em: http://www.if.ufrgs.br/ienci/artigos/ Artigo_ID199/v13_n3_a2008.pdf. Acesso em: 06 ago. 2018.

VIECHENESKI, J. P.; SILVEIRA, R. M. C. F. Alfabetização científica por meio da abordagem CTS: um caminho viável à formação de cidadãos. In.: SIMPÓSIO NACIONAL DE ENSINO DE CIÊNCIA E TECNOLOGIA, 1., 2012, Ponta Grossa. Anais [...] Ponta Grossa: UTFPR, 2012. Disponível em: http:// www.sinect.com.br/anais2012/html/artigos/ciencia/11.pdf. Acesso em 09 fev. 2019.

\section{LIVROS DIDÁTICOS ANALISADOS}

CARnevalle, M. R. Coleção Projeto Araribá Ciências 8º ano. Curitiba: Moderna, 2014.

GEWANDSNAJDER, F. Coleção Teláris Ciências 8 ano. Porto Alegre: Ática, 2013.

LOPES, S. Coleção Investigar e Conhecer Ciências $8^{\circ}$ ano. São Paulo: Saraiva, 2015.

PEREIRA, A. M.; SANTANA, M.; WALDHEIM, M. Coleção Apoema Ciências $8^{\circ}$ ano. São Paulo: do Brasil, 2015. 